\title{
Achieving Full Anatomical Correction in Girls with cloacal anomalies: A Necessity or an Overdoing?
}

\section{Original Article}

\author{
Amr Abdelhamid AbouZeid
}

Department of Pediatric Surgery, Faculty of Medicine, Ain Shams University, Cairo, Egypt

\begin{abstract}
Purpose: To highlight a different concept for the urogenitoplasty in the management of cloaca and its possible implications on functional and cosmetic outcome.

Patients and Methods: The study included six cases of cloaca who were recently managed during the period 2011 through 2015. Regarding urogenitoplasty, two cases with low urogenital confluence had a short common channel and were managed by introitoplasty in one and partial urogenital sinus mobilization in the other. One case with high distended vagina communicating close to the bladder neck was managed by vaginal pull-through, while keeping the common urogenital sinus to act as urethra. In between, three intermediate cases were also managed by introitoplasty, while keeping them with the common urogenital sinus uncorrected.

Results: The follow-up period ranged from 2 to 6.5 years. Apart from the hypoplastic external genitalia, all cases included in the study had minimal perineal scaring compared with old cases that underwent extensive perineal 'urogenital' dissection. Urinary and stool incontinence was observed in one case that was associated with caudal regression syndrome. Another case that underwent vaginal pull-through had poor evacuation of the urinary bladder; this was managed by anticholinergics and clean intermittent catheterization. The rest of cases had voluntary bowel movements and spontaneous voluntary micturition.

Conclusion: Considering the potential risk and complications of separating the vagina from the urethra in some cases of cloaca, it might be better from the functional and cosmetic point of view to perform just introitoplasty while keeping these girls with the common urogenital sinus uncorrected.
\end{abstract}

Key Words: Anorectal anomalies, cloaca, introitoplasty, MRI, urogenital sinus.

Received: 31 Janurary 2019, Accepted: 23 February 2019

Corresponding Author: Amr Abdelhamid AbouZeid, MD, Department of Pediatric Surgery, Faculty of Medicine, Ain Shams University, Cairo, Egypt, Tel.: +20 111656 0566, Fax: +20 224830 833, E-mail: amrabdelhamid@hotmail.com.

ISSN: 2537-0014

\section{INTRODUCTION}

The cloaca is one of the complex anomalies in pediatric surgery. It represents a separate entity of anorectal anomalies and a special challenge to the surgeon $^{[1]}$. Efforts of successive imminent pediatric surgeons in the field have led to great progress in understanding and providing clear guidelines for the management of the anorectal component of the anomaly ${ }^{[2-4]}$. However, dealing with the associated common urogenital sinus abnormality often remained an obstacle for achieving an overall satisfactory outcome in cloaca ${ }^{[5]}$. The reason may be related to the embryological and anatomical intimate relation between the urethra and the vagina ${ }^{[6]}$, besides the delicate blood supply of these fine structures, which makes their separation an extremely difficult procedure $^{[7]}$. On the contrary, the robust submucosal blood supply of the rectum ${ }^{[7]}$, together with the plenty and continuity of colonic tissue above, makes mobilization of the rectum a relatively more straightforward procedure.'

Over the past 15 years, we have been concerned with studying the anatomical variations of cloacal anomalies, evolution of the surgical techniques, and consequent functional and cosmetic outcomes. We faced limitations in applying the current classification ${ }^{[8]}$ setting a cutoff value of $3-\mathrm{cm}$ length of the common channel to differentiate between simple and complex forms ${ }^{[5,9]}$. Therefore, we shifted to a new stratification system based on preoperative MRI examination that relates the level of the urogenital confluence to the back of pubic symphysis. Moreover, we have found it more practical to discriminate between the anorectal and urogenital components of the anomaly during surgical planning, as both components do not always share the same degree of severity in the same patient ${ }^{[8]}$. Separate surgical planning has encouraged separating the repair to be performed in two successive stages, the anorectoplasty followed by urogenitoplasty. Staging the repair of such a complex anomaly has the advantage of decreasing surgical stress to which the infant is exposed during lengthy reconstructive procedures.

In this report, we focused on the urogenital 
component trying to demonstrate a different concept for the urogenitoplasty in the management of cloaca, and its possible implications on functional and cosmetic outcome.

\section{PATIENTS AND METHODS}

The study included cases of cloaca that were recently managed by the author during the period 2011 through 2015. "Owing to the retrospective nature of the study, an IRB number was not required, and the study was approved through expedited review by the scientific committee."

All cases were initially managed by colostomy; vaginostomy was needed in selected cases. Echocardiography and pelviabdominal ultrasound represent necessary screening tools for possible associated cardiac and renal anomalies (Table 1). The definitive repair was delayed after the age of three

Table 1: summary of data of six cases of cloaca included in the study, their associated anomalies and follow up.

\begin{tabular}{|c|c|c|c|c|c|c|c|c|c|}
\hline Case & $\begin{array}{l}\text { Age at } \\
\text { time of } \\
\text { repair }\end{array}$ & $\begin{array}{l}\text { Grading of } \\
\text { urogenital } \\
\text { confluence }\end{array}$ & $\begin{array}{l}\text { Urogenital } \\
\text { repair }\end{array}$ & Sacrum & $\begin{array}{c}\text { Spinal } \\
\text { anomalies }\end{array}$ & $\begin{array}{c}\text { Associated renal } \\
\text { anomalies }\end{array}$ & $\begin{array}{c}\text { Age at } \\
\text { follow-up }\end{array}$ & $\begin{array}{l}\text { Follow-up } \\
\text { of upper } \\
\text { urinary tract }\end{array}$ & $\begin{array}{c}\text { Urinary } \\
\text { continence }\end{array}$ \\
\hline 1 & $12 \mathrm{~m}$ & Low & $\begin{array}{l}\text { Introitoplasty } \\
\text { (cut-back) }\end{array}$ & 2 pieces & $\begin{array}{l}\text { High cord } \\
\text { termination } \\
\text { (T12) }\end{array}$ & single right kidney & $7.5 \mathrm{yr}$ & No dilatation & $\begin{array}{l}\text { Urinary } \\
\text { incontinent }\end{array}$ \\
\hline 2 & $5 \mathrm{~m}$ & Low & PUM & 4 pieces & - & $\begin{array}{l}\text { single left kidney } \\
\quad+\text { minimal } \\
\text { hydronephrosis }\end{array}$ & $3.5 \mathrm{yr}$ & No dilatation & $\begin{array}{c}\text { Voluntary } \\
\text { micturition (dry } \\
\text { by daytime) }\end{array}$ \\
\hline 3 & $48 \mathrm{~m}$ & Intermediate & $\begin{array}{l}\text { Introitoplasty } \\
\text { (cut-back+ } \\
\text { posterior } \\
\text { skin flap) }\end{array}$ & $\begin{array}{l}5 \text { pieces } \\
\text { (fusion) }\end{array}$ & - & - & $6 \mathrm{yr}$ & No dilatation & $\begin{array}{c}\text { Voluntary } \\
\text { micturition (dry } \\
\text { by daytime }\end{array}$ \\
\hline 4 & $44 \mathrm{~m}$ & Intermediate & $\begin{array}{l}\text { Introitoplasty } \\
\text { (cut-back) }\end{array}$ & $\begin{array}{l}5 \text { pieces } \\
\text { (fusion) }\end{array}$ & - & Left pelvic kidney & $6.5 \mathrm{yr}$ & No dilatation & $\begin{array}{l}\text { Voluntary } \\
\text { micturition (dry } \\
\text { by daytime; } \\
\text { occasional urge } \\
\text { incontinence }\end{array}$ \\
\hline 5 & $5 \mathrm{~m}$ & Intermediate & $\begin{array}{c}\text { Introitoplasty } \\
\text { (cut-back+ } \\
\text { posterior } \\
\text { skin flap) }\end{array}$ & $\begin{array}{l}5 \text { pieces } \\
\text { (fusion) }\end{array}$ & - & - & $3 \mathrm{yr}$ & No dilatation & $\begin{array}{c}\text { Voluntary } \\
\text { micturition (dry } \\
\text { by daytime }\end{array}$ \\
\hline 6 & $26 \mathrm{~m}$ & High & $\begin{array}{c}\text { Vaginal } \\
\text { pull-through }\end{array}$ & complete & - & $\begin{array}{c}\text { Bilateral } \\
\text { hydroureteonephrosis }\end{array}$ & $8 \mathrm{yr}$ & $\begin{array}{c}\text { Bilateral } \\
\text { moderate } \\
\text { hydronephrosis }\end{array}$ & $\begin{array}{c}\text { Poor bladder } \\
\text { evacuation; CIC + } \\
\text { anticholinergics }\end{array}$ \\
\hline
\end{tabular}

months. We incorporated noncontrast pelvic MRI routinely in the preoperative assessment, in addition to conventional contrast studies (colostogram and genitogram) and endoscopy.

Regarding the classification of cloaca, we used separate grading for the anorectal and urogenital components. This has been discussed in detail in previous reports. Grading of the anorectal component depends on identifying the level of the rectal descent in relation to the bodies of corresponding vertebrae $^{[10]}$. This can be best demonstrated in lateral contrast radiography studies or sagittal pelvic MRI examination. A high rectum above the level of the third sacral vertebra (S3) usually will need assistance from above (abdominal/laparoscopic) for effective mobilization.

On the other hand, the level of the urogenital confluence in relation to the back of the pubic symphysis was used to classify cloaca into three types: low, intermediate, and high (Figure 1). A low confluence has a short common channel that is amenable for either limited introitoplasty (without extending the dissection anterior to the urethra; (Figure 2$)^{[8]}$ or partial urogenital sinus mobilization 

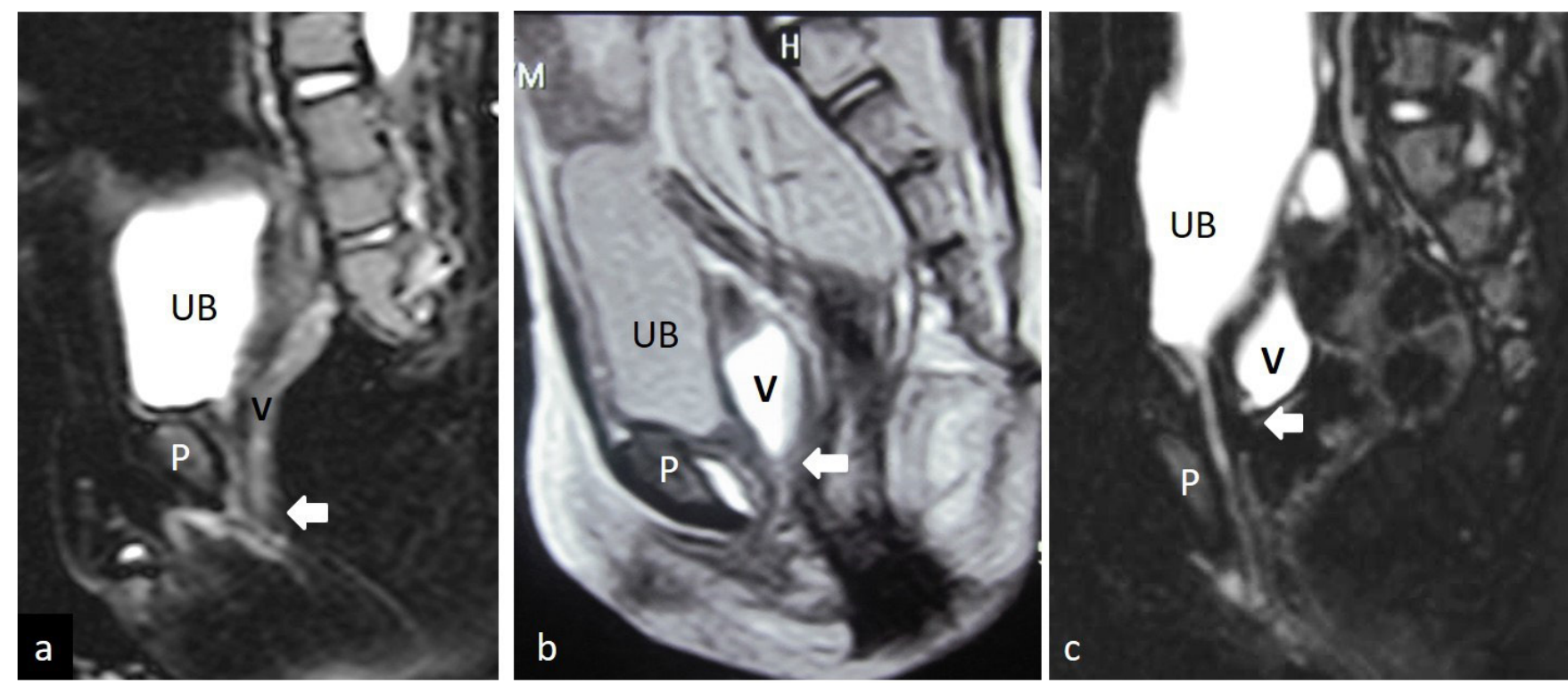

Fig. 1: MRI stratification of cloaca based on the level of the urogenital confluence (white arrow) in relation to the pubic symphysis (P). (a) Type 1 (low): urogenital confluence at or below the level of the lower end of the pubis. (b) Type 2 (intermediate): urogenital confluence at the level of the mid portion of pubis. d) Type 3 (high): urogenital confluence above the level of the upper end of pubis. UB, urinary bladder; V, vagina.
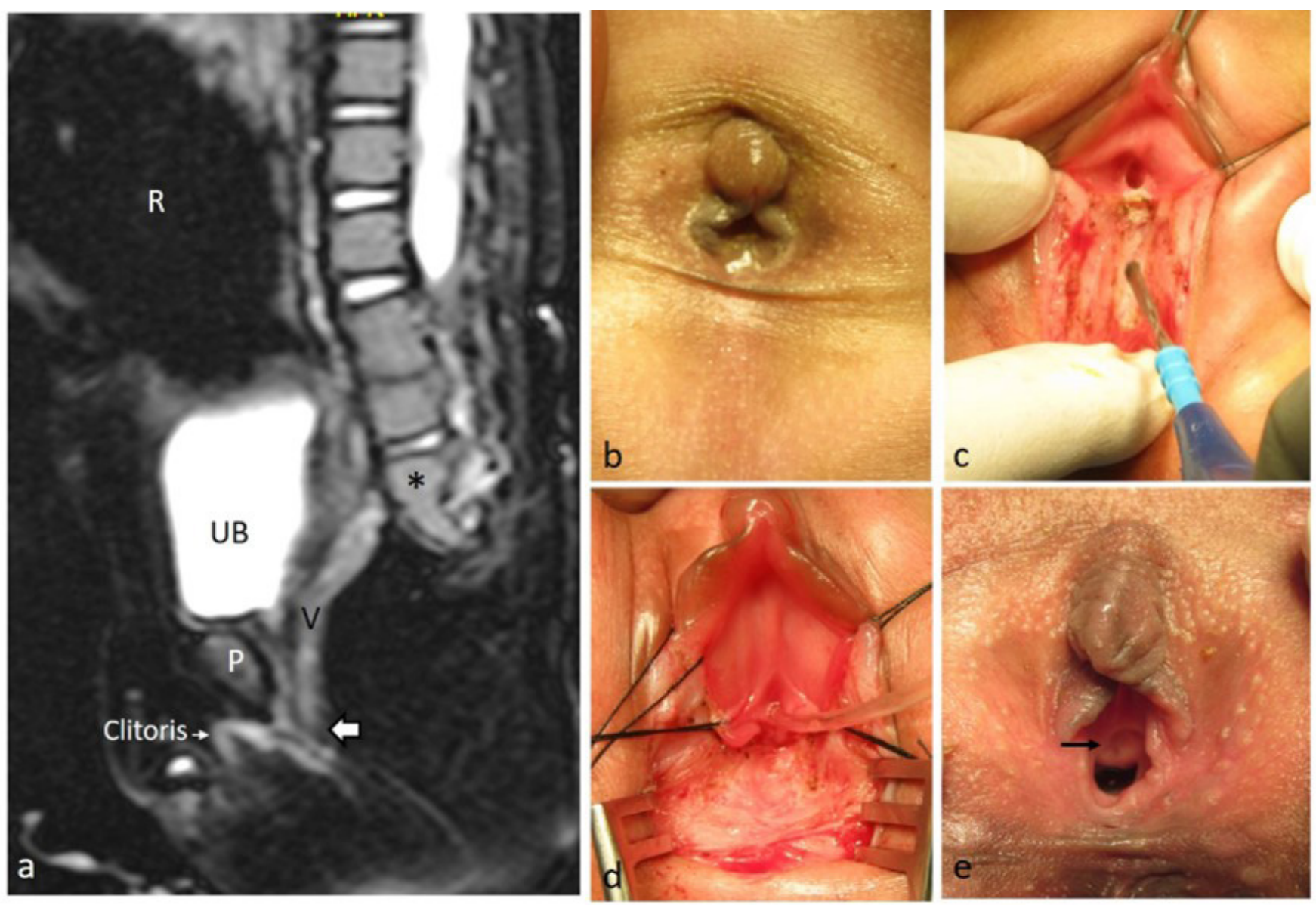

Fig. 2: Simple introitoplasty to manage low urogenital confluence in a case of cloaca (12-month old). (a) Midsagittal MRI (fat suppressed T2WI): note the high rectum $(\mathrm{R})$; urinary bladder $(\mathrm{UB})$; pubic symphysis $(\mathrm{P})$; dysplastic sacrum $(*)$; clitoris (small arrow). Thick white arrow is pointing to the level of urogenital confluence at lower end of pubis. (b) Hypoplastic external genitalia around a single perineal orifice. (c, d) Cut-back through common urogenital sinus to widen the introitus and expose urethral and vaginal orifices. (e) Appearance at 5-year follow-up (the black arrow points to urethral orifice). 

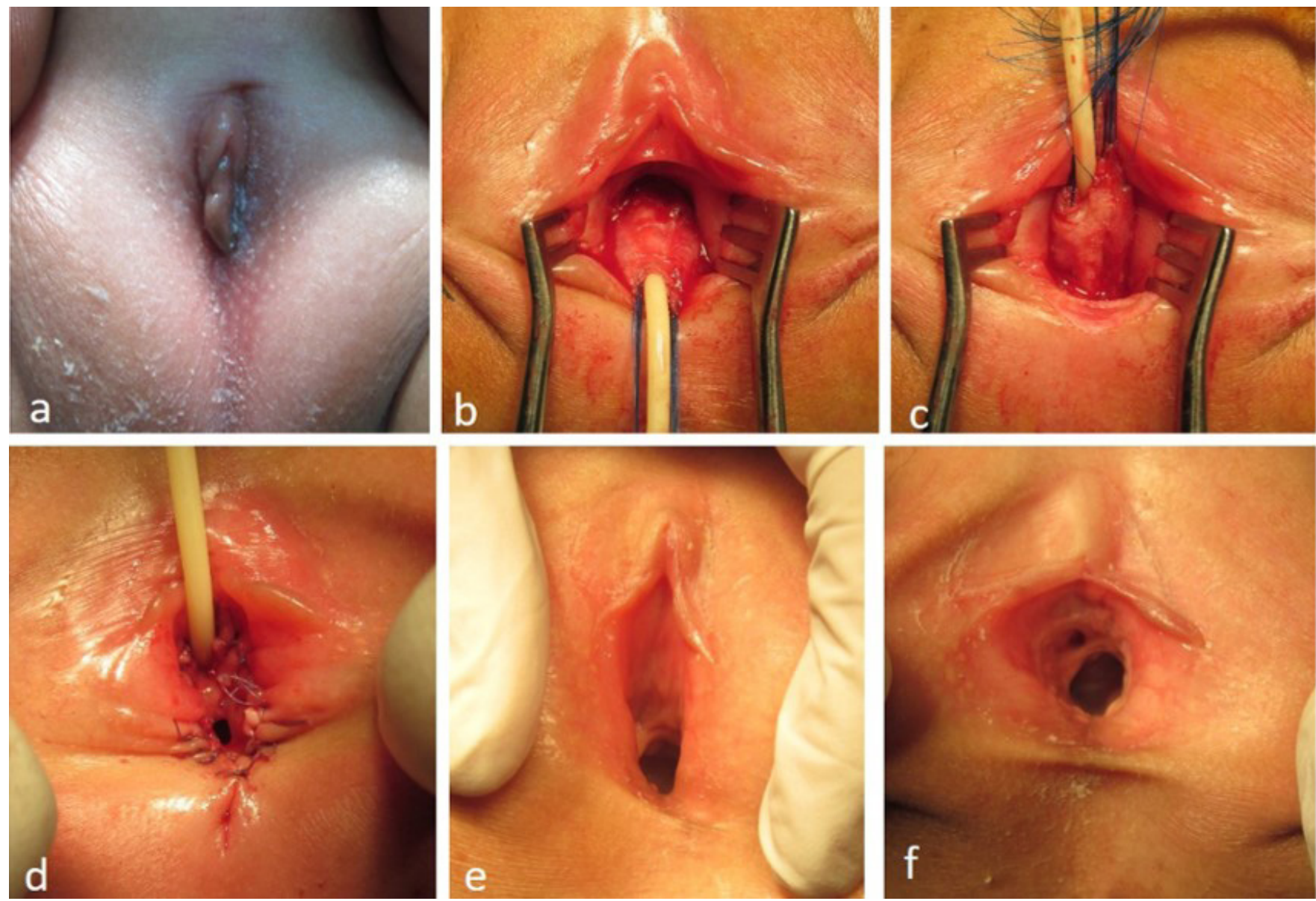

Fig. 3: Partial urogenital sinus mobilization (PUM) to manage low urogenital confluence in a case of cloaca (5 months old). Note: the patient had undergone anorectoplasty (PSARP) at a previous separate stage. (a) Hypoplastic external genitalia around a single perineal orifice. (b, c) Dissection and mobilization of the urogenital sinus as one unit. (d) Fixation of urethral and vaginal orifices in the vestibule. (e, f) External appearance of genitalia three years later at followup (at time of removal of excess anal mucosa).

(PUM; Figure 3) ${ }^{[11]}$. A high confluence with the vagina communicating close to the bladder neck will need to separate the vagina from the urinary tract and keep the common urogenital sinus to act as urethra ${ }^{[10,12]}$.

Although we can expect some sort of consensus on the management of cloaca at both ends of the spectrum $^{[10,12]}$, the wide range that falls in between (intermediate types) represents a dilemma. The current most popular solutions may be either posterior sagittal ano-recto-vaginoplasty or total urogenital sinus mobilization ${ }^{[13,14]}$. Here, we propose to manage these intermediate cases in a way similar to cases 

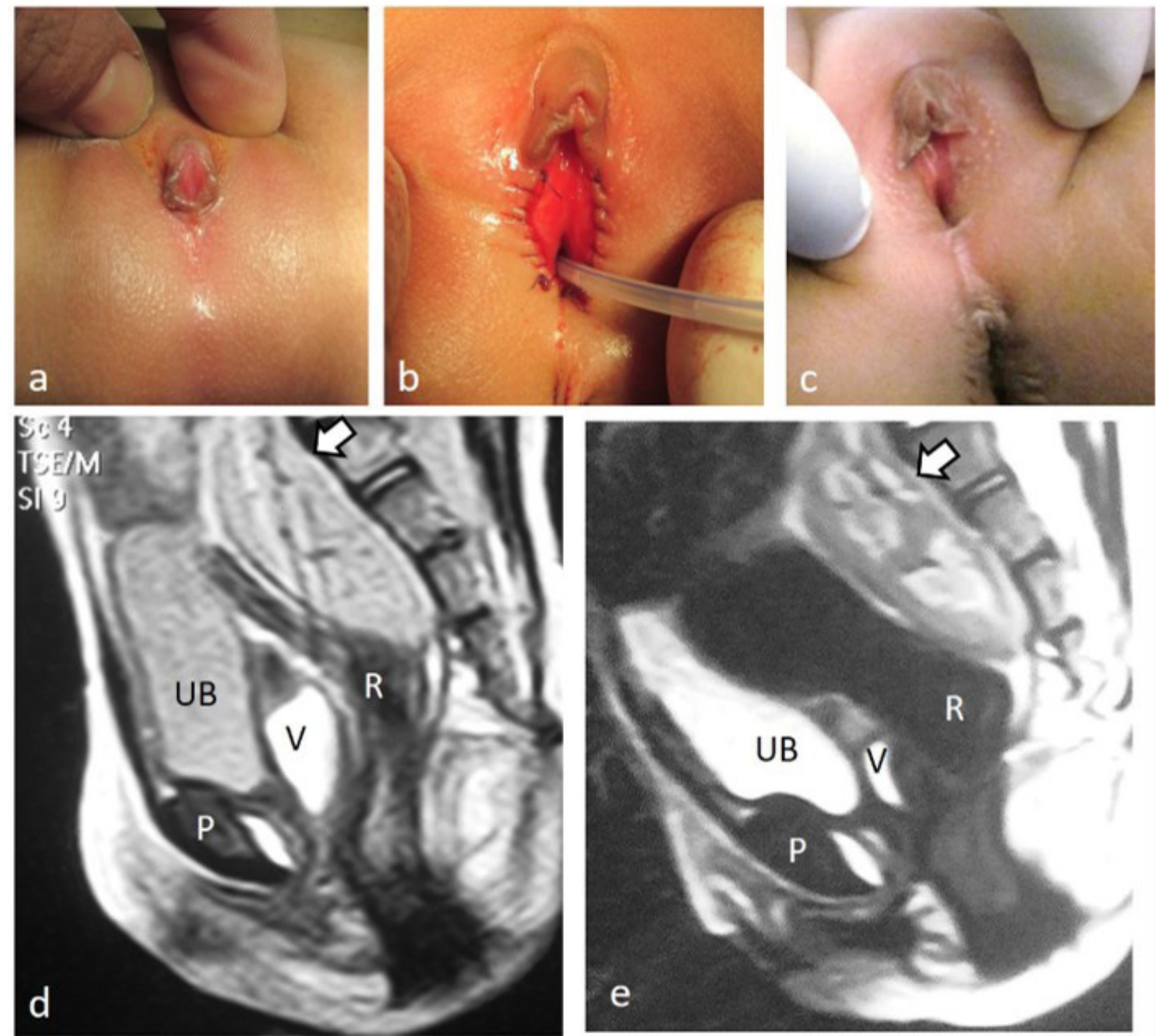

Fig. 4: A case of cloaca (44 months old) with intermediate type of urogenital confluence managed by simple introitoplasty, while keeping the urogenital confluence uncorrected. Note: The patient had undergone anorectoplasty at a previous separate stage (laparoscopic-assisted anorectal pull-through for a high rectum). (a) Hypoplastic external genitalia around a single perineal orifice; (b) cut-back through urogenital sinus to widen the introitus and improve urine outflow through the common urogenital sinus; (c) follow-up after 20 months (there is still a common external path for both urinary and genital tracts). The improvement in urine outflow is demonstrated in preoperative and postoperative MRI examinations ( $\mathrm{d}$ and e, respectively) showing decrease in vaginal distension (V) after the introitoplasty. P, pubis; UB, urinary bladder; V, vagina; R, rectum. Note: the presence of a pelvic kidney (white arrow) behind the rectum in MRI.

with a low confluence, in other words, to keep them with the common urogenital sinus uncorrected, while performing introitoplasty or PUM to improve urine outflow through the common sinus (Fig. 4).

\section{RESULTS}

The study included six cases of cloaca. All cases underwent colostomy at birth, and one of them required vaginostomy. Their age at referral for definitive repair ranged from 5 to 48 months (mean, 23.3; median, 19). In four cases, we staged the repair starting by the anorectoplasty to be followed by urogenitoplasty few weeks later.
In two cases, the rectum was high necessitating abdominal assistance in one and laparoscopic assistance in the other, whereas a perineal approach $(\text { PSARP })^{[3]}$ was used in the remaining four cases.

Regarding the common urogenital sinus, the urogenital confluence was low in two cases, which were managed by introitoplasty in one (Figure 2) and PUM in the other (Figure 3). A third case had a high confluence with a distended vagina communicating close to the bladder neck and causing bilateral hydroureteronephrosis (Figure 5a); this case was initially managed by vaginostomy and later by 
vaginal separation and pull-through while keeping the common sinus to act as urethra (Figure $5 \mathrm{~b}-\mathrm{d}$ ). In between, we had three cases (intermediate type) that
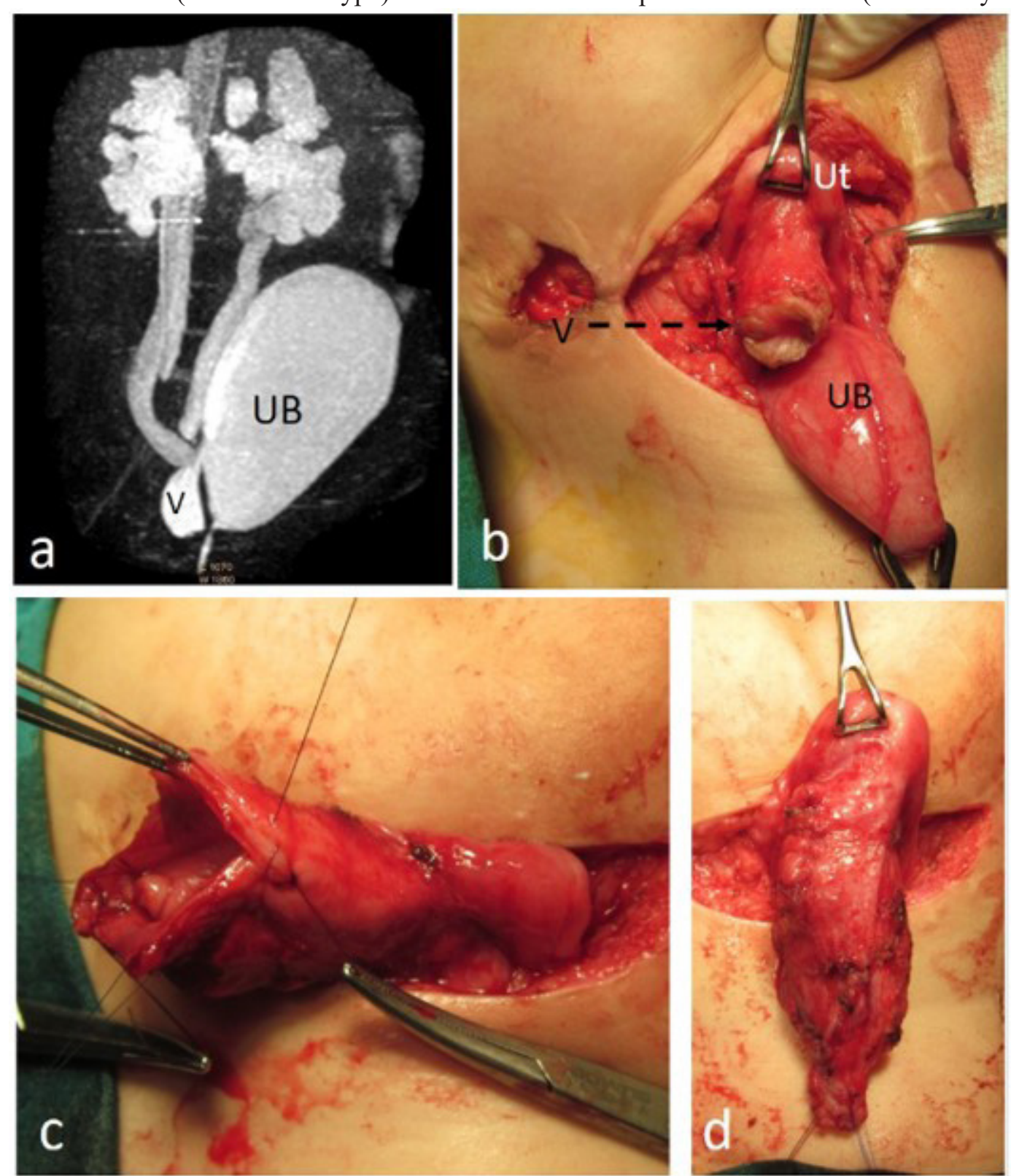

Fig. 5: A case of cloaca (26 months old) with high urogenital confluence. (a) Magnetic resonance urography showing the vaginal 'take-off' very close to the bladder neck. Note the distended bladder (UB) and bilateral hydroureteronephrosis; the vagina (V) is seen behind the bladder. (b, c, d) Operative photographs of vaginal pull-through: (b) the vaginostomy (V) is detached from the abdominal wall. Ut, uterus; UB, urinary bladder. (c) The vagina is separated from the back of the bladder and reconstructed to form a tube; (d) the vagina is ready for a pull-through procedure.

tracts). Introitoplasty was performed as either simple cut-back through the common sinus and perineal skin (Figure 4b) or combined with a posterior 'Fortunoff' skin flap ${ }^{[15]}$ to widen the introitus (Table 1).

The follow-up period ranged from 2 to 6.5 years. Clinical assessment included both cosmetic and functional outcomes (urinary and bowel control). Ultrasound examination (every 6 months and then yearly) was important to follow-up for dilatation of the upper urinary tract (Table 1), and postvoiding residual urine volume represented a good indicator for bladder evacuation. Apart from the hypoplastic external genitalia, all cases included in the study had minimal perineal scaring compared with old cases that underwent extensive perineal 'urogenital' dissection (Figure 6). Poor functional outcome (urinary and stool incontinence) was observed in one case, which was associated with caudal regression syndrome (sacral agenesis and high spinal cord termination; Figure 1). Another case with high urogenital confluence that underwent vaginal pullthrough had poor evacuation of the urinary bladder; this was managed by anticholinergics and clean intermittent catheterization (CIC), and later underwent Mitrofanoff procedure. The rest of cases had voluntary 

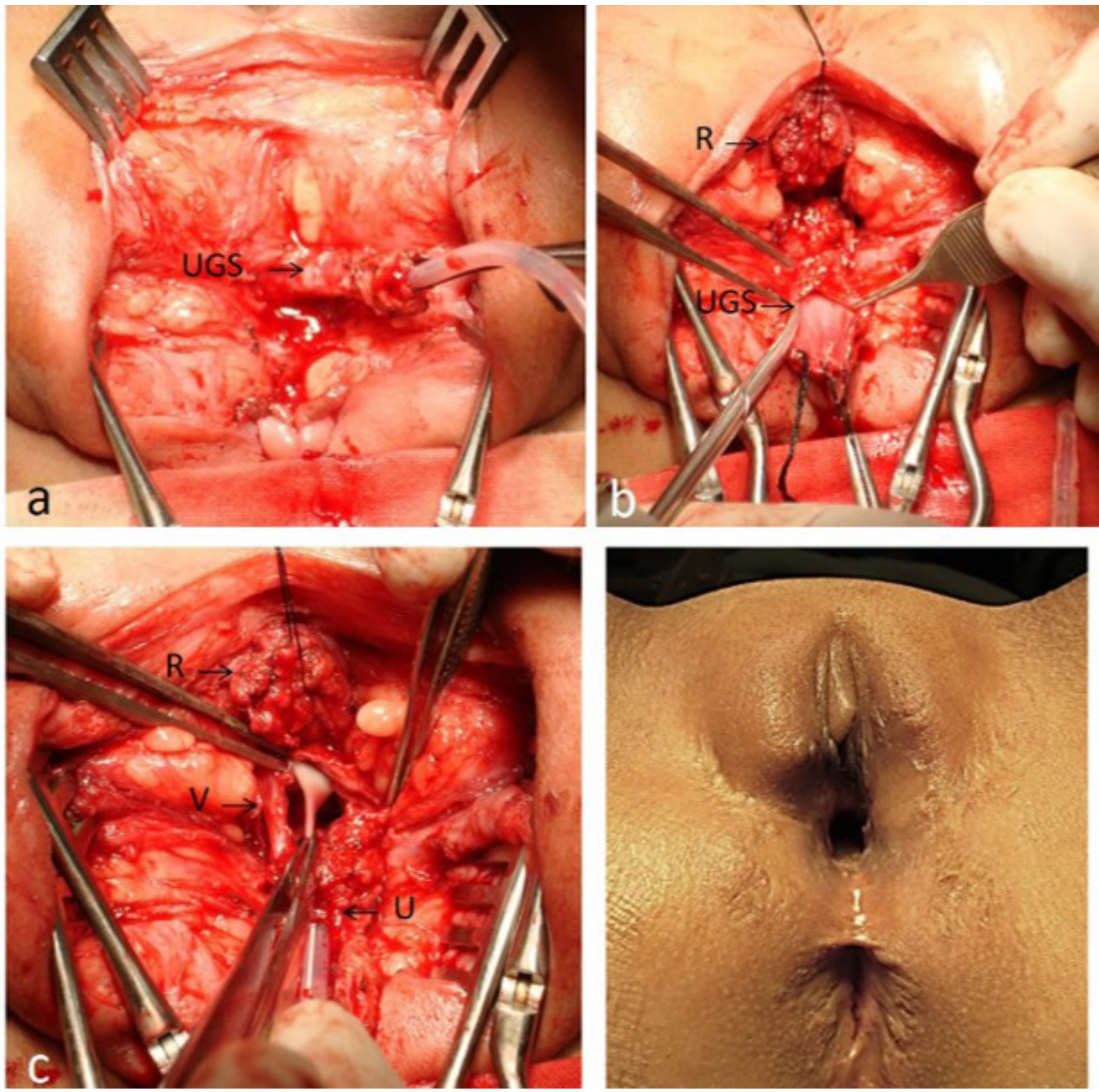

Fig. 6: Total urogenital sinus mobilization (TUM) for a case of cloaca (8-month old) from a previous cohort. (a) Posterior sagittal approach with the patient in the prone position; dissection and mobilization of the common urogenital sinus (UGS). (b) Separation of the rectum (R) and incision through the mobilized urogenital sinus. (c) Now we can identify three separate structures: rectum (R), septated vagina (V), and urethra (U). (d) Cosmetic appearance of external genitalia 7 years later. The picture was taken at the time of operation for revision of stenosed appendicostomy of a self-catheterizable channel (Mitrofanoff). Note the presence of tissue loss and scaring affecting the vestibule (golf-hole appearance), also affecting both labia majora (more on the left side).

bowel control and spontaneous voluntary micturition (Table 1). Constipation was a common finding and sometimes was associated with soiling that showed good response to stimulant laxatives.

\section{DISCUSSION}

The goals of surgical management in cases of cloaca are to preserve renal function as a priority, and to preserve the continence potential, as well as sexual and reproductive function in these patients $^{[9]}$. Unfortunately, these goals have not been always achievable even in patients managed in highly specialized centers all over the world ${ }^{[1,5,16]}$. Sometimes, the unfavorable outcome may be related to innate 'uncorrectable' factors: renal dysplasia,
Mullerian hypogenesis, and neurogenic factors (caudal regression). Most cases of cloaca are repaired early during infancy; therefore, it may be difficult to judge whether the unfavorable outcome was owing to congenital factors or a 'second hit' related to the corrective surgery ${ }^{[5]}$.

In the management of congenital anomalies, achieving full anatomical correction is sometimes impossible or even unindicated. Intestinal malrotation is a good example in pediatric surgery. The corrective surgery (famous Ladd's procedure) does not aim to restore normal anatomy but rather to put the intestine in the best position of function (which is certainly nonanatomical) to avoid the development of mid gut 
volvulus. Similarly, we thought that the persistent worldwide reporting on the unsatisfactory outcome in cases of cloaca ${ }^{[17]}$ may be a stimulus to change our surgical concept in the management of these cases ${ }^{[18]}$. Achieving full anatomical correction in girls with cloaca (separate urethral and vaginal perineal orifices) is sometimes impossible without compromising the blood supply of these delicate organs and their potential for normal urinary continence $\mathrm{e}^{[16,19,20]}$.

Under certain circumstances, weighing the risk of ischemic complications and urinary incontinence that may result from complete vaginal mobilization against the expected benefit, we may suggest another option of partial correction. We can perform some sort of introitoplasty or partial mobilization and keep these girls with a common path for both urinary and genital tracts. Of course this suggestion is not suitable for all cases of cloaca like those with a high vagina communicating very close to the bladder neck and causing obstruction to the lower urinary tract. In such cases, the vagina must be separated to relieve obstruction, to be followed by vaginal pull-through. The latter can be a direct pull-through if the vaginal length allows; otherwise, more commonly a piece of bowel can be used to bridge the gap down to the perineum $^{[10]}$.

In absence of hydrocolpos, the timing for vaginoplasty in cases of cloaca (early versus late) has been a matter of debate ${ }^{[17]}$. Some authors support early reconstruction, whereas others would prefer to delay vaginal surgery after puberty with no clear evidence on either side ${ }^{[17]}$. Our suggestion for initial incomplete urogenital correction may be supported by those who advocate for late intervention, as still we did not lose the chance for delayed vaginal reconstruction. However, we have some observations that may indicate that girls with common urogenital sinus may not necessarily need further major vaginal reconstruction after puberty. During performing contrast studies through the common channel (genitograms), the inserted catheter has been shown to pass preferentially into the vagina, and in many times, we fail to opacify the urinary bladder and urethra. This observation is supported by reports on successful management of hydrocolpos in cases of cloaca by CIC of the vagina in the neonatal period $^{[4,21]}$. Therefore, we can expect the common urogenital sinus not to interfere with vaginal coitus in these cases. Moreover, a common urogenital sinus is a normal finding in some animals ${ }^{[4]}$, and there have been few historical reports on rare human cases with uncorrected cloaca who got pregnant ${ }^{[22]}$. Interestingly, Crouch et al. ${ }^{[23]}$ reported on four women with congenital adrenal hyperplasia (persistent urogenital sinus) who had not undergone surgery and were similar to controls regarding a variety of sexual outcomes including vaginal penetration.
The rationale behind keeping some selected cases of cloaca with uncorrected common urogenital sinus can be summarized in the following points:

1. Vaginal mobilization is often described as a difficult and lengthy procedure whose results are not always reproducible ${ }^{[8,10,24]}$.

2. There is always risk of ischemic complications that may result from dissection and mobilization of such fine structures with delicate blood supply (urethra and vagina) ${ }^{[8]}$. The risk becomes very high with combined perineal and abdominal dissection ${ }^{[12]}$.

3. The expected benefit from full vaginal mobilization regarding sexual and reproductive function is already compromised in cases of cloaca by the high incidence of associated Mullerian anomalies. Pregnancy has been described to be extremely rare and risky in cases with repaired cloaca ${ }^{[17]}$. Moreover, studies have shown urinary incontinence to be associated with raised sexual anxiety and fear of sexual relationships ${ }^{[17]}$.

4. By applying a limited surgical approach, we can eliminate the theoretical risk of 'iatrogenic' urinary incontinence ${ }^{[5,19,20]}$, which may be considered one of the most distressing sequels for both parents and children. Moreover, we can obtain much less perineal scaring that can result from extensive mobilization needed for full correction. Perineal scaring has been reported to reduce sexual sensitivity and sexual satisfaction ${ }^{[17]}$.

5. A last point that would be raised by supporters of early vaginal reconstruction is providing easy access from below for CIC. The latter may be needed by a high percentage of cases of repaired cloaca that experience poor bladder evacuation $^{[19,25,26]}$. However, the reconstructive surgery itself might have been responsible for (or aggravating) bladder dysfunction in some of these cases ${ }^{[5]}$. Nevertheless, girls who need CIC to evacuate their bladder usually will depend on a permanent self-catheterizable channel through the abdomen rather than the difficult access through the perineum.

In this report, we propose a different surgical concept for the management of cases of cloaca by keeping some selected cases with the common urogenital sinus uncorrected. Not only can we avoid the possible risk of urinary incontinence that represents the main burden for parents and children in the school age, but also we expect to gain other benefits regarding the sexual and reproductive functions. As the anatomy of the urogenital sinus usually allows the introducing catheter to pass preferentially into the 
vagina, we do not expect it to interfere with vaginal coitus in the future. Moreover, a woman with less perineal scaring and normal continence is expected to have better sexual life.

Besides the small number of cases, the age at follow-up remains a major limitation in this study; we still need longer follow-up for these cases to assess their postpubertal menstrual and sexual function. Another point of concern may be related to the risk of recurrent urinary tract infections when these girls become sexually active. Applying a technique that avoids extensive dissection for the proximal urethra and vagina carries a theoretical advantage regarding the preservation of pelvic innervation and urinary continence ${ }^{[20]}$; however, still this has to be proven by long-term follow-up and more objective urodynamic studies. Although this may be considered a preliminary report waiting for the more important postpubertal period, yet the outcome in the school age has been very encouraging, and of course we did not loose the chance of shifting to other surgical options if turned to be necessary.

\section{CONCLUSION}

Considering the potential risk and complications of separating the vagina from the urethra in some cases of cloaca, it might be better from the functional and cosmetic point of view to perform just introitoplasty while keeping these girls with the common urogenital sinus uncorrected.

\section{CONFLICTS OF INTEREST}

There are no conflicts of interest.

\section{REFERENCES}

1. Versteegh HP, van Rooij IA, Levitt MA, Sloots CE, Wijnen RM, de Blaauw I. Long-term follow-up of functional outcome in patients with a cloacal malformation: a systematic review. J Pediatr Surg 2013; 48:2343-2350.

2. Stephens FD. Congenital imperforated rectum, recto-urethral and recto-vaginal fistulae. Aust N Z J Surg 1953; 22:161-172.

3. DeVries PA, Pena A. Posterior sagittal anorectoplasty. J Pediatr Surg 1982; 17: 638-643.

4. Hendren H. Cloacal malformations: experience with 105 cases. J Pediatr Surg 1992; 27:890-901.

5. Caldwell BT, Wilcox DT. Long-term urological outcomes in cloacal anomalies. Semin Pediatr Surg 2016; 25:108-111.

6. Haderer JM, Pannu HK, Genadry R, Hutchins
GM. Controversies in female urethral anatomy and their significance for understanding urinary continence: observations and literature review. Int Urogynecol J 2002; 13:236-252.

7. Bischoff A, Levitt MA, Breech L, Hall J, Pena A. Vaginal switch-a useful technical alternative to vaginal replacement for select cases of cloaca and urogenital sinus. J Pediatr Surg 2013; 48:363-366.

8. Levitt MA, Pena A. Cloacal malformations: lessons learned from 490 cases. Semin Pediatr Surg 2010; 19:128-138.

9. Rink RC, Herndon CDA, Cain MR, Kaffer $\mathrm{M}$, Dussinger AM, King SJ, Casale AJ. Upper and lower urinary tract outcome after surgical repair of cloacal malformations: a three-decade experience. BJU Int 2005; 96: 131-134.

10. Bischoff A. The surgical treatment of cloaca. Semin Pediatr Surg 2016; 25:102-107.

11. Rink RC, Metcalfe PD, Kaefer MA, Casale AJ, Meldrum KK, Cain MP. Partial urogenital mobilization: a limited proximal dissection. J Pediatr Urol 2006; 2:351-356.

12. Wood RJ, Reck-Burneo CA, Dajusta D, Ching $\mathrm{C}$, Jayanthi $\mathrm{R}$, Bates $\mathrm{DG}$, et al. Cloaca reconstruction: a new algorithm which considers the role of urethral length in determining surgical planning. J Pediatr Surg 2018; 53:90-95.

13. Pena A. Total urogenital mobilization-an easier way to repair cloacas. J Pediatr Surg 1997; 32:263-267.

14. Versteegh HP, Sloots CEJ, Wolffenbuttel KP, de Jong JR, Sleeboom C, Feitz WF, et al. Urogenital function after cloacal reconstruction, two techniques evaluated. J Pediatr Urol 2014; 10:1160-1164.

15. Fortunoff S., Lattimer J. K., Edson M. Vaginoplasty technique for female pseudohemaphrodites. Surg Gyn Obstet 1964; 118:545.

16. Versteegh HP, Sutcliffe JR, Sloots CEJ, Wijnen RMH, de Blaauw I. Postoperative complications after reconstructive surgery for cloacal malformations: a systematic review. Tech Coloproctol 2015; 19:201-207.

17. Fernando MA, Creighton SA, Wood D. The long-term management and outcomes of cloacal anomalies. Pediatr Nephrol 2015; 30:759-765. 
18. Liu XT, Li HT, Li L, Chen L, Wang LJ, Ma $\mathrm{K}$, et al. Chronic urogenital sinus expansion in reconstruction of high persistent cloaca. Pediatr Surg Int 2012; 28:835-840.

19. Leclair MD, Gundetti M, Kiely EM, Wilcox DT. The surgical outcome of total urogenital mobilization for cloacal repair. J Urol 2007; 177:1492-1495.

20. Kalfa N, Liu B, Cao M, Vilella M, Hsieh M, Baskin LS. 3-dimensional neuroanatomy of the human fetal pelvis: anatomical support for partial urogenital mobilization in the treatment of urogenital sinus. J Urol 2008; 180:1709-1715.

21. Chalmers DJ, Rove KO, Wiedel CA, Tong S, Siparsky GL, Wilcox DT. Clean intermittent catheterization as an initial management strategy provides for adequate preservation of renal function in newborns with persistent cloaca. J Pediatr Urol 2015; 11:211.e1211.e4.

22. Pena A, Bischoff A: History of the Treatment of Anorectal Malformations. In: Pena A, Bischoff A. Surgical treatment of anorectal problems in children. Springer Heidelberg 2015; pp: 1-16.
23. Crouch NS, Liao LM, Woodhouse CR, Conway GS, Creighton SM. Sexual function and genital sensitivity following feminizing genitoplasty for congenital adrenal hyperplasia. J Urol 2008; 179:634-638.

24. Levitt MA, Bischoff A, Pena A. Pitfalls and challenges of cloaca repair: how to reduce the need for reoperations. J Pediatr Surg 2011; 46:1250-1255.

25. Camanni D, Zaccara A, Capitanucci ML, Mosiello G, Iacobelli BD, De Gennaro M. Bladder after total urogenital mobilization for congenital adrenal hyperplasia and cloacadoes it behave the same? J Urol 2009; 182:1892-1897.

26. Matsui F, Shimada K, Matsumoto F, Obara T, Kubota A. Bladder function after total urogenital mobilization for persistent cloaca. J Urol 2009; 182:2455-2459. 